Artículo científico

Volumen 30(3):659-679. Septiembre-diciembre, 2019

e-ISSN 2215-3608, doi:10.15517/am.v30i3.35038

http://www.revistas.ucr.ac.cr/index.php/agromeso

\title{
Distribución potencial y nicho fundamental de Moniliophthora spp en cacao de América y África ${ }^{1}$
}

\section{Potential distribution and fundamental niche of Moniliophthora spp in cocoa of America and Africa}

\author{
Julián Esteban Másmela-Mendoza²
}

1 Recepción: 31 de octubre, 2018. Aceptación: 21 de marzo, 2019. Este trabajo formó parte del proyecto de investigación derivado del curso semestral de modelamiento de nichos ecológicos de la maestría en Biología, Posgrado de la Universidad de Antioquia, Medellín, Colombia.

2 Universidad de Antioquia (UdeA), Grupo de Investigación de Biotransformación. Calle 67 \#53 - 108, Medellín, Antioquia, Colombia. julian. masmela@udea.edu.co (https://orcid.org/0000-0002-6019-1449).

\section{Resumen}

Introducción. Las especies de Moniliophthora spp. son endémicas de Sudamérica e infectan los cultivos de cacao de América. Objetivo. El objetivo del estudio fue analizar la distribución potencial y el nicho fundamental de Moniliophthora roreri $(\mathrm{Mr})$ y $\mathrm{M}$. perniciosa $(\mathrm{Mp})$ en América y África. Materiales y métodos. Los registros de ocurrencia fueron obtenidos de una revisión bibliográfica. Se utilizaron variables bioclimáticas como predictores en el modelo de nicho de máxima entropía (MaxEnt) y para su visualización en Niche Analyst 3.0. Resultados. Las zonas donde se registró mayor probabilidad de ocurrencia de $M r$ fueron Esmeraldas y Los Ríos, Ecuador, zonas costeras de Costa Rica, Santander y Antioquia de Colombia, y para Mp los Estados de Bahía y Acré de Brasil. Las variables que más influyeron en la distribución de $M r$ están asociadas a las precipitaciones. Las condiciones relacionadas con la temperatura fueron más importantes en el modelo de $M p$. Se identificó el riesgo de invasión de $M r$ en las regiones de Acré y Pará, Brasil. La transferencia de los modelos evidenció el potencial de invasión de $M r$ y $M p$ en los cultivos de cacao en África. El nicho fundamental de los patógenos y el cacao presentó valores de similitud medios, mientras que, el nicho de las especies de hongos mostró una baja similitud. La baja similitud de los nichos de los patógenos y las diferencias en las variables bioclimáticas que afectan su distribución se podrían relacionar a un proceso de partición del nicho. Conclusión. Se identificaron las regiones geográficas con una mayor distribución potencial de los patógenos y las características bioclimáticas que favorecerían su probabilidad de presencia en los cultivos de cacao de América. Es necesario regular el transporte de material vegetal y equipo contaminado entre regiones para evitar la introducción de los patógenos en cultivos de cacao sanos.

Palabras claves: biogeografía, Theobroma cacao, ecología microbiana, hongos patógenos, interacción huésped patógeno.

\begin{abstract}
Introduction. Moniliophthora spp. species are endemic from South America and infect America's cocoa crops. Objetive. The objective of the study was to analyze the potential distribution and the fundamental niche of
\end{abstract}




\begin{abstract}
Moniliophthora roreri $(\mathrm{Mr})$ and $\mathrm{M}$. perniciosa $(\mathrm{Mp})$ in America and Africa. Materials and methods. The occurrence records were obtained from a bibliographic review. Bioclimatic variables were used as predictors in the maximum entropy niche model (MaxEnt) and for its visualization in Niche Analyst 3.0. Results. The areas where $M r$ was most likely to occur were Esmeraldas and Los Ríos, Ecuador, coastal zones of Costa Rica, Santander and Antioquia of Colombia, and for $M p$ the States of Bahia and Acré of Brazil. The variables that most influenced the distribution of $M r$ are those associated with precipitation. Temperature-related conditions were more important in the $M p$ model. The risk of $M r$ invasion was identified in the Acre and Pará regions, Brazil. The transfer of the models evidenced the potential of $\mathrm{Mr}$ and $\mathrm{Mp}$ invasion in cocoa crops in Africa. The fundamental niche of pathogens and cocoa showed average similarity values, while the niche of fungal species showed a low similarity. Low pathogen niche similarity and differences in bioclimatic variables affecting pathogens distribution were related to a process of niche partitioning. Conclusion. Geographical regions with a greater potential distribution of pathogens and bioclimatic characteristics that would favor their probability of presence in America's cocoa crops were identified. It is necessary to regulate the transport of contaminated plant material and equipment between regions to avoid the introduction of pathogens in healthy cocoa crops.
\end{abstract}

Keywords: biogeography, Theobroma cacao, microbial ecology, pathogenic fungi, host pathogen relations.

\title{
Introducción
}

La pudrición blanda del fruto o moniliasis producida por la infección de Moniliophthora roreri H. C. Evans, Stalpers, Samson \& Benny $(M r)$, y la enfermedad de la escoba de bruja causada por el hongo Moniliophthora perniciosa (Stahel) Aime ( $M p)$, son las dos patologías que generan mayores pérdidas en los cultivos de cacao (Theobroma cacao L) de América. Ambas especies de hongos son endémicas y originarias de Sudamérica tropical, conforman un clado monofilético dentro de la familia Marasmiaceae, orden Agaricales (Basidiomycota) (Aime y Phillips-Mora, 2005; Barbosa et al., 2018). A pesar de su cercanía filogenética, cada especie ataca órganos vegetales específicos de la planta y poseen distintos hospederos. $M r$ es un hongo especialista que crece e infecta exclusivamente los frutos de las especies de Herrania spp y Theobroma spp (familia Malvaceae) (Evans, 2016b), mientras que $M p$ puede afectar distintos tejidos de la planta: brotes vegetativos, cojines florales, las mazorcas, $\mathrm{y}$ causar síntomas en especies de las familias Malvaceae, Solanaceae, Bignoniaceae y Malpighiaceae (Griffith et al., 2003; Evans, 2016a). El ciclo vital de ambos patógenos está dividido en dos fases: una biótrofa o parasítica y una necrótrofa o saprofítica, es por ello que se clasifican como hongos hemibiótrofos. Los hongos pueden alterar el equilibrio hormonal de sus hospederos, generando hipertrofias y, posteriormente originar necrosis del tejido (Evans et al., 2013).

Durante la fase biótrofa, los síntomas causados por $M r$ son las protuberancias o gibas en los frutos, manchas aceitosas, y al pasar a la fase necrótrofa se observa la pudrición del tejido y el desarrollo de micelio externo en esporulación (Evans, 2016b). El principal síntoma de $M p$ en su fase biótrofa es la producción de hipertrofias denominadas comúnmente como escobas de bruja, además de la proliferación de brotes axilares, la pudrición de frutos y el desarrollo de basidiocarpos en la fase necrótrofa (Meinhardt et al., 2008; Evans, 2016a).

Los lugares geográficos de origen y endemismo de cada patógeno son diferentes. $\mathrm{Mr}$ es un patógeno originario de Colombia y es en este país donde se encuentra la mayor diversidad genética poblacional, con el primer registro de la enfermedad en 1817 (Phillips-Mora et al., 2007; Ali et al., 2015). Uno de los problemas actuales en el manejo de la moniliasis es la ampliación de su rango de distribución, expandiéndose debido a la introducción accidental humana hacia países de Sur y Centroamérica en los cuales no había registros de la enfermedad, como en Panamá 
(1951) (Orellana, 1956), Costa Rica (década del 70) (Enríquez y Suárez, 1978), Guatemala (década 1990) (Evans et al., 2002), Belice y México (2005) (Phillips-Mora et al., 2006a; b).

Hacia el sur del continente $\mathrm{Mr}$ ha expandido su área de distribución durante el siglo XX. El hongo se dispersó hacia Ecuador a mediados de la década de 1980 (Evans, 1986), traspasando la barrera geográfica de los Andes al registrarse en Perú en 1988, hasta ser reportado en la región del Cuzco (Evans et al., 2002) y en zonas de mayor altitud como Bolivia (Phillips-Mora et al., 2015).

La escoba de bruja se originó en Brasil. Se considera que la región amazónica occidental del país es el centro endémico de $M p$ y los estados de Acre y el Amazonas occidental contienen las poblaciones con mayor diversidad genética del patógeno (Purdy y Schmidt, 1996; Artero et al., 2017; Patrocínio et al., 2017), con un posible primer registro del hongo en 1785 (Silva, 1987). El biotipo C de la especie es endémico de la Amazonía (Purdy y Schmidt, 1996), zona desde la cual se ha dispersado, invadiendo y causando grandes pérdidas en los cultivos de las regiones locales del Brasil, principalmente hacia el estado de Bahía llegando a la región en 1989 (Artero et al., 2017).

El principal factor limitante de la producción de cacao en Brasil es la escoba de bruja, mientras que, en los países suramericanos como Colombia, Ecuador y Perú, y en países del centro como Costa Rica y México, la principal causa de pérdida es la moniliasis. En los cultivos de cacao de Brasil no se han reportado árboles enfermos por $M r$, y se considera una enfermedad de seguimiento y cuarentena, debido al alto riesgo de diseminación (Leandro-Muñoz et al., 2017; Barbosa et al., 2018), y al delimitar el país con zonas donde el hongo está presente.

La incidencia de la escoba de bruja es baja en los cultivos del Sur y Centro de América. Ambas especies de hongos son nativas de América (Aime y Phillips-Mora, 2005), y no se han reportado en otros continentes cacaoteros como Asia y África (Phillips-Mora et al., 2007). Una de las preocupaciones actuales es el riesgo de invasión de los patógenos por introducción accidental humana en África occidental, ya que podría ser crítica (Phillips-Mora et al., 2007; Leandro-Muñoz et al., 2017) para una región que produce aproximadamente el $70 \%$ de cacao en el mundo (Artero et al., 2017).

El término de nicho ha sido ampliamente discutido en la ecología. Unos de los conceptos clásicos son los términos de nicho fundamental y nicho realizado propuestos por Hutchinson (1957). El nicho fundamental fue definido como un hipervolumen de las variables ambientales, las cuales influyen para que una especie se mantenga viable en un área geográfica sin necesidad de inmigración, mientras que el concepto de nicho realizado incorpora las interacciones bióticas de una especie con otros organismos, que determinan el uso real del nicho fundamental.

El concepto de nicho actualmente empleado en la construcción de modelos, que recopila y enriquece las teorías de otros autores es el propuesto por Soberón y Peterson (2005), definido mediante el diagrama BAM. El nicho ecológico de una especie es la expresión y descripción conjunta de la combinación entre las interacciones bióticas (B), los requerimientos ambientales (condiciones abióticas y recursos) (A) y la posibilidad de una especie de alcanzar áreas accesibles, debido a la capacidad de dispersión y de movimiento (M) (Soberón y Peterson, 2005). Estos tres factores interactuantes (BAM) regulan la distribución, la dinámica poblacional de una especie y están intrínsecamente relacionados con la fisiología y el comportamiento de un organismo.

El modelo de nicho ecológico puede ser analizado para las interacciones de parasitismo en los sistemas agrícolas. Las poblaciones de hospederos y parásitos en los patosistemas comparten algunas condiciones ambientales adecuadas para ambos, y de alguna forma, están compartiendo alguna fracción o volumen de sus nichos ecológicos (Soberón, 2007; Escobar y Craft, 2016). Las condiciones ambientales pueden influir en la diseminación de los propágulos, el periodo de incubación y en el proceso de infección desarrollados por un fitopatógeno (Agrios, 2005). Igualmente, pueden existir factores abióticos que favorezcan la patogenicidad y reduzcan la resistencia a la enfermedad de materiales vegetales, existiendo zonas geográficas con espacios ambientales idóneos para la enfermedad (Agrios, 2005; Cubillos, 2017). Con base en la importancia de la estimación de la distribución y el nicho de un parásito y su huésped, los modelos descritos anteriormente han sido utilizados en la evaluación del riesgo de invasión de un fitopatógeno, en el análisis de su establecimiento y en la dispersión de enfermedades en 
los agroecosistemas (Phillips et al., 2006; Bogosian et al., 2012; Kumar et al., 2014; Escobar y Craft, 2016; OsorioAlmanza et al., 2017).

Con base en las diferencias en la distribución, los riesgos de diseminación de la enfermedad y las características particulares de la biología y ecología de las especies, el objetivo del estudio fue analizar la distribución potencial y el nicho fundamental de Moniliophthora roreri $(\mathrm{Mr})$ y M. perniciosa $(\mathrm{Mp})$ en América y África.

\section{Materiales y métodos}

\section{Fuente de datos de registros de presencia}

Los registros de presencia de Theobroma cacao L., se obtuvieron por medio de una búsqueda en la base GBIF (2018). Se realizó una revisión bibliográfica en las principales bases de datos (Science Direct, Scopus, Springer, Academic Search Complete, Scielo y Redalyc), para recopilar los registros de las enfermedades en países de Sudamérica y Centroamérica. Para la selección de los artículos científicos se tuvo en cuenta una descripción de las zonas con nombres de veredas, fincas y coordenadas, además de que la publicación recogiera un alto número de ocurrencias y que tuviera un muestreo que abarcara una amplia distribución geográfica. Para una mayor veracidad de la presencia se tuvo en cuenta que se incluyera una descripción específica de los síntomas producidos por cada enfermedad, el aislamiento en medios de cultivo, la identificación morfológica y taxonómica por técnicas de amplificación y secuenciación de regiones como los espacios transcritos internos (ITS) de las regiones de ADNr18S.

\section{Organización y depuración de la base de datos}

Se seleccionaron los registros de presencia de T. cacao L. que tuvieran coordenadas en el sistema WGS84 y que hubieran sido recogidos de datos de especímenes en herbario y por observación directa. Con el fin de reducir el sobreajuste del modelo debido a agrupamientos espaciales de presencias, se utilizó la herramienta "spatially rarefy occurrence data tool" de SDMToolBOX 2.0, la cual reduce a un único punto las coordenadas cercanas a una distancia Euclidiana elegida de $5 \mathrm{~km}^{2}$ (Brown, 2014).

\section{Predictores del nicho para el hospedero y los patógenos}

Las capas de las variables bioclimáticas de tipo continuo se obtuvieron del Global Climate Data - WorldClim versión 2 (Fick y Hijmans, 2017), con una resolución temporal de 2,5 arc-min en formato TIFF.

Para el modelo de nicho de T. cacao L. (Tc) se utilizó como área de acceso Centro y Suramérica. Los países de Centro y Sudamérica donde ha sido registrada la presencia de $M r$ se escogieron como área accesible para la especie. Para $M p$ se utilizó Brasil como zona de acceso, debido a que la mayoría de los registros de otros países no contenían información específica de las localidades, y teniendo en cuenta que la mayor incidencia de la enfermedad está reportada en ese país. Las coberturas descargadas se recortaron según el área accesible de las especies en capas ráster, y se realizó la respectiva conversión de formatos TIFF a ASCII, bajo la misma resolución, extensión y proyectadas bajo el mismo sistema de coordenadas geográficas mundial (WGS84), mediante la herramienta SDMToolBOX 2.0 (Brown, 2014) articulada a ArcGIS 10,4 de ESRI.

Con el fin de eliminar las variables que tuvieran un valor de correlación alto, las cuales pueden influir en el análisis de las curvas de respuesta y en la importancia de las variables en el modelo, se procedió a realizar un primer modelo para cada especie con las diecinueve variables ambientales disponibles de WordlClim versión 2.0, recortadas para cada área de acceso, y el modelo se efectuó a través del algoritmo de máxima entropía (Maxent) 
con las condiciones descritas en el siguiente ítem de la metodología. A partir de los resultados de este modelo, se seleccionaron las diez variables que obtuvieron los valores más altos del índice de Jackknife, el cual mide la importancia de cada dato climático en la ganancia del entrenamiento del modelo (Phillips et al., 2006). Las variables con mayor importancia para cada modelo se pusieron en las primeras posiciones de organización en la función remover variables altamente correlacionadas de la caja de herramientas SDMtoolbox 2.2 activada en ArCGIS 10.4. Esta función estableció una correlación de Pearson entre las diez variables más importantes respecto a las restantes, buscando retener algunas, y arroja una agrupación de estas, según un umbral máximo de correlación $(0,6 ; 0,7 ; 0,8)$. El máximo límite de correlación elegido para las variables de entrada del modelo de $T c$ fue 0,6 . Para los patógenos se adoptó el criterio de 0,7. Para el procedimiento anterior se siguieron las indicaciones descritas en la guía de usuario elaborada por Brown (2014).

\section{Modelo de máxima entropía (Maxent)}

El modelo de distribución para hospedero-patógenos se realizó mediante el algoritmo de Máxima Entropía, empleando el programa MaxEnt 3.4.1 (Phillips et al., 2016). El primer ejercicio realizado fue el modelo de distribución de T. cacao L. El modelo de distribución del cacao recortado para cada área de acceso de $M r$ y $M p$, se utilizó como cobertura en los parámetros de integración para la elaboración del modelo de las especies de patógenos.

Para la configuración del modelamiento en MaxEnt se usaron los siguientes parámetros:

El algoritmo se construyó con un máximo de 500 iteraciones y un mínimo de convergencia de 0,00001 ; se generaron 25 réplicas del modelo, reservando un $20 \%$ para la evaluación, y un $80 \%$ para el entrenamiento. Para la validación del modelo se remuestrearon los datos por medio de muestreos con reemplazo (bootstrapping). Para el modelo de $T c$ se aplicó la regla de umbral de igualdad de sensibilidad y especificidad de entrenamiento, y para el modelo de los fitopatógenos se utilizó la configuración de umbral de presencia mínima de entrenamiento.

Se activó la creación de curvas de respuesta para cada variable, y la importancia de las variables en el modelo se estimó mediante la prueba Jackknife. Se seleccionó la salida logística, la cual arroja una medida de tasas de ocurrencia relativa o idoneidad relativa, descrita como una probabilidad de presencia entre 0 (ausencia de la especie) y 1 (presencia).

Para la evaluación de los modelos se utilizó el cálculo del área bajo la curva (AUC) a partir de la curva operativa característica del receptor (ROC, por sus siglas en inglés), parámetros establecidos por Phillips et al. (2006). Los valores de AUC cercanos a 1 significan que el modelo tiene un alto poder de predicción (Phillips y Dudík, 2008).

\section{Transferencias espaciales de los nichos de $M r$ y $M p$ a áreas con potencial de invasión}

El modelo de nicho de $M r$ se transfirió a Brasil, mientras que el modelo de $M p$ se proyectó en los países centro y suramericanos, e igualmente ambos fueron transferidos al continente africano. Los modelos se proyectaron en el programa MaxEnt con la inclusión de un directorio con las capas ambientales específicas para cada modelo y recortados a las áreas de invasión.

\section{Análisis del nicho fundamental}

Se utilizó la aplicación Niche Analyst 3.0 y el diagrama de flujo desarrollados por Qiao et al. (2016). Se seleccionaron de cada especie las tres variables ambientales con mayor contribución según el valor de Jackknife, para generar la nube de fondo de entrada, con el fin de visualizar el espacio ambiental y obtener las simulaciones del nicho $(\mathrm{N})$ virtual fundamental elaborado a partir de los registros de presencia, y calculado mediante el elipsoide 
de mínimo volumen. De cada modelo se obtuvieron sus atributos de volumen y se cuantificó el volumen de solapamiento del nicho fundamental de las tres especies interactuantes, con el fin de calcular la similitud de los nichos (0 a 1) a través del índice Jaccard (Qiao et al., 2016).

\section{Resultados}

\section{Registros de presencia y selección de predictores}

Se obtuvieron un total de 1567 registros de presencia de T. cacao L. (Tc) después de la filtración de la información descargada del GBIF. Para Moniliophthora roreri H. C. Evans, Stalpers, Samson \& Benny (Mr) se obtuvieron un total de 192 registros de presencia, provenientes de los estudios realizados por Phillips-Mora et al. (2006a), Phillips-Mora et al. (2006b), Phillips-Mora et al. (2007), Ali et al. (2015) y Suárez-Contreras (2016). Del hongo Moniliophthora perniciosa (Stahel) Aime ( $M p)$, se recolectaron un total de 161 registros en Brasil, recopilados de los estudios de Scarpari et al. (2005), Leal et al. (2007), Shaw y Vandenbon (2007), Osorio-Solano et al. (2012), Gramacho et al. (2016), Artero et al. (2017), Patrocínio et al. (2017).

De acuerdo con el proceso de filtración de las variables, los factores ambientales seleccionados para el modelo de distribución de $T c$ fueron la BIO2 [rango medio diurno - promedio mensual (temperatura máxima - temperatura mínima)], BIO3 [Isotermia (BIO2 / BIO7) (* 100)], BIO5 (temperatura máxima del mes más caluroso), BIO17 (precipitación promedio del trimestre del año más seco), BIO18 (precipitación promedio del trimestre del año más caluroso) y BIO19 (precipitación promedio del trimestre del año más frío). Para el modelo de $M r$ fueron filtradas las variables BIO3, BIO6 (temperatura mínima del mes más frío), BIO8 (temperatura media del trimestre del año más húmedo), BIO13 (precipitación del mes más húmedo), BIO15 [estacionalidad de la precipitación (coeficiente de variación)] y la BIO18.

Las variables $\mathrm{BIO} 2, \mathrm{BIO}$, BIO6, BIO14 (precipitación promedio del mes más seco), BIO16 (precipitación del trimestre del año más húmedo) y la BIO18 se incluyeron como las capas ambientales de entrada para el modelo de $M p$.

\section{Distribución potencial y variables importantes del modelo de nicho de $T c$}

Las probabilidades de ocurrencia relativa más altas de la especie $(0,5-0,8)$ se registraron en las áreas tropicales del Amazonas de Brasil, Colombia, Perú y Ecuador, y en las zonas costeras del Atlántico de los países centroamericanos (Figura 1).

El AUC promedio de entrenamiento para las ejecuciones repetidas del modelo fue de $0,895 \pm 0,003$, el cual indica que tiene un buen poder de predicción. El modelo incrementó su ganancia con las variables de precipitación del trimestre del año más cálido (BIO18), la isotermia (BIO3) y la temperatura máxima del mes más cálido (BIO 5). Al analizar las curvas de respuesta (Figura 2), la probabilidad de ocurrencia del cacao es mayor cuando la precipitación de los tres meses más secos del año es de 700 a $800 \mathrm{~mm}$, y disminuyó al incrementar el promedio de lluvia, en zonas donde la isotermia es del 70 al $80 \%$ y con temperaturas máximas de 25 a $30{ }^{\circ} \mathrm{C}$.

\section{Distribución potencial y variables importantes del modelo de distribución de los patógenos}

Las áreas con una muy alta probabilidad de ocurrencia relativa ( 0,7 a 1$)$ de la moniliasis se ubican en las zonas costeras del Ecuador en estados como Esmeraldas y Los Ríos, las zonas de Santander y Norte de Santander de Colombia, regiones de Antioquia y las zonas costeras del Pacífico de Costa Rica (Figura 1). 

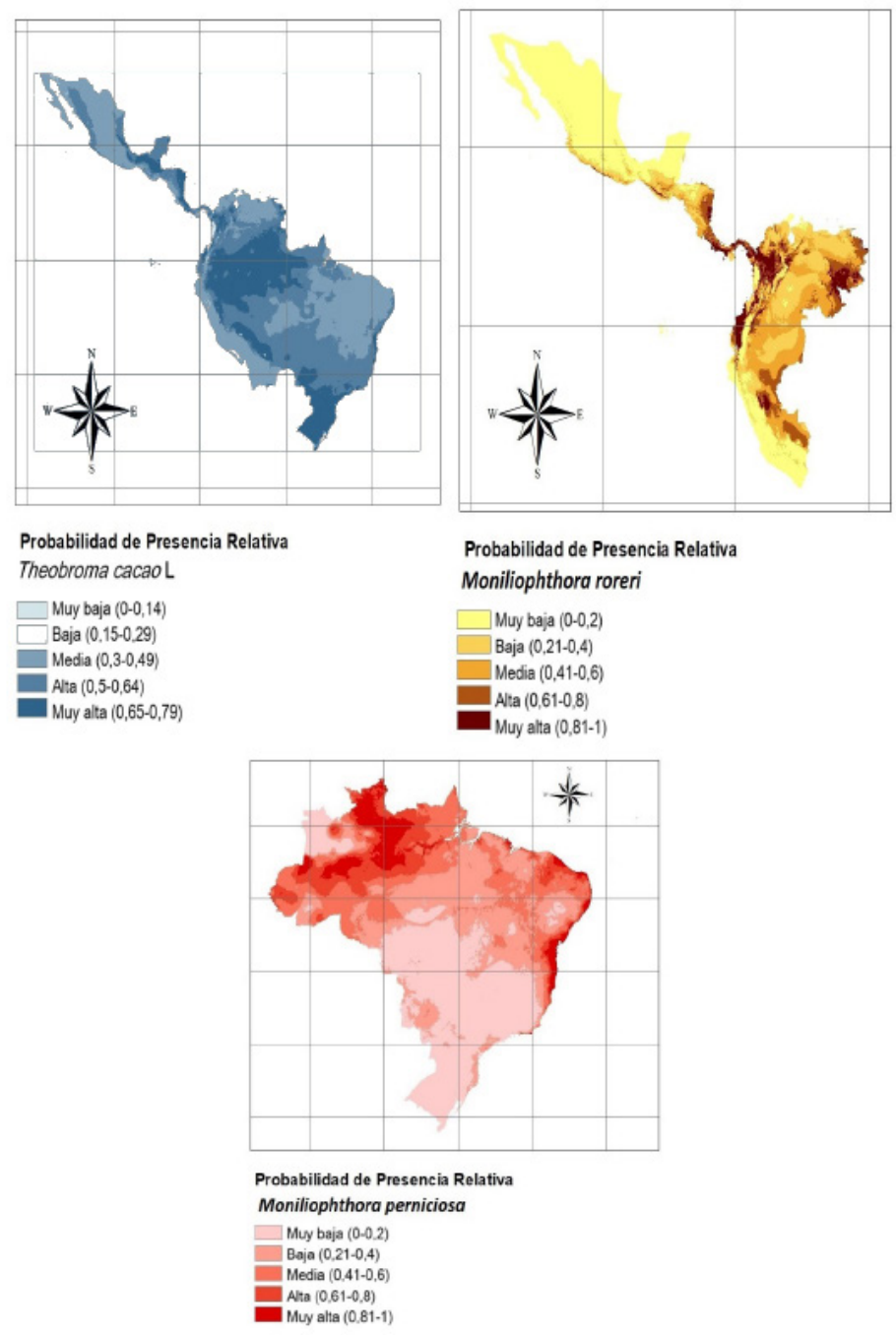

Figura 1. Distribución geográfica potencial de T. cacao L, M. roreri y M. perniciosa $(\alpha=95 \%$ nivel de confianza, media de las 25 réplicas del modelo).

Figure 1. Potential geographic distribution of T. cacao L, M. roreri and $M$. perniciosa $(\alpha=95 \%$ confidence level, average of the 25 replicas of the model).

La capacidad predictora del modelo de $M r$ es buena, reflejado en un valor de desempeño de AUC de $0,868 \pm$ 0,013. Las variables que más influyeron en la distribución de la moniliasis son la precipitación del trimestre del año más cálido (BIO18), la precipitación del mes más húmedo (BIO13), la estacionalidad de la precipitación (coeficiente de variación) (BIO15) y la isotermia (BIO3) (Figura 3). Mayores porcentajes de isotermia, precipitaciones entre 500 y $600 \mathrm{~mm}$ durante el mes más húmedo, lluvias promedio de 1000 a $1200 \mathrm{~mm}$ durante los tres meses más calurosos y probabilidades de ocurrencia relativas altas de cacao, favorecen la probabilidad de presencia de la moniliasis (Figura 3). 

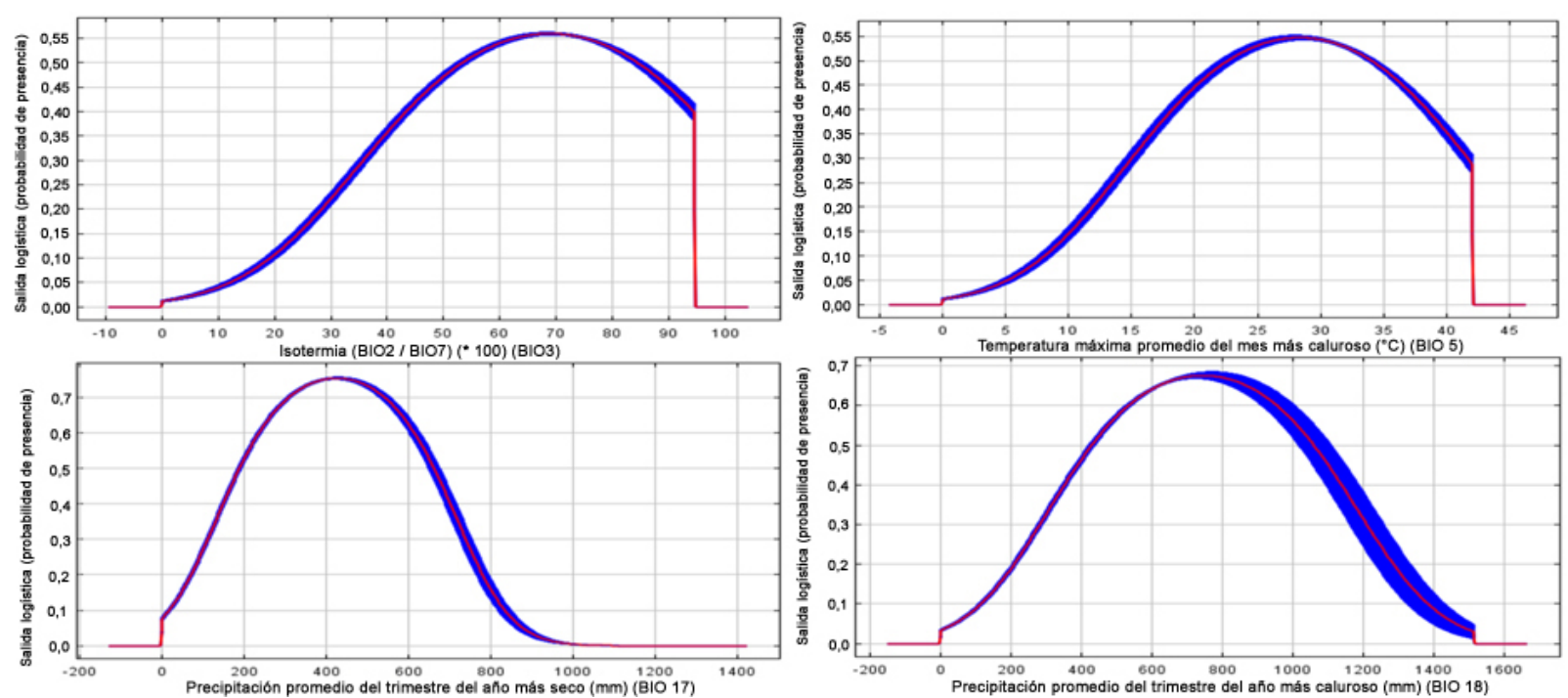

Figura 2. Curvas de respuesta de la probabilidad de ocurrencia relativa del cacao (Theobroma cacao) en función de los predictores más importantes (valor Jackknife) en su modelo de distribución.

Figure 2. Response curves of the probability of relative occurrence of cocoa (Theobroma cacao) as a function of the most important predictors (Jackknife value) in its distribution model.
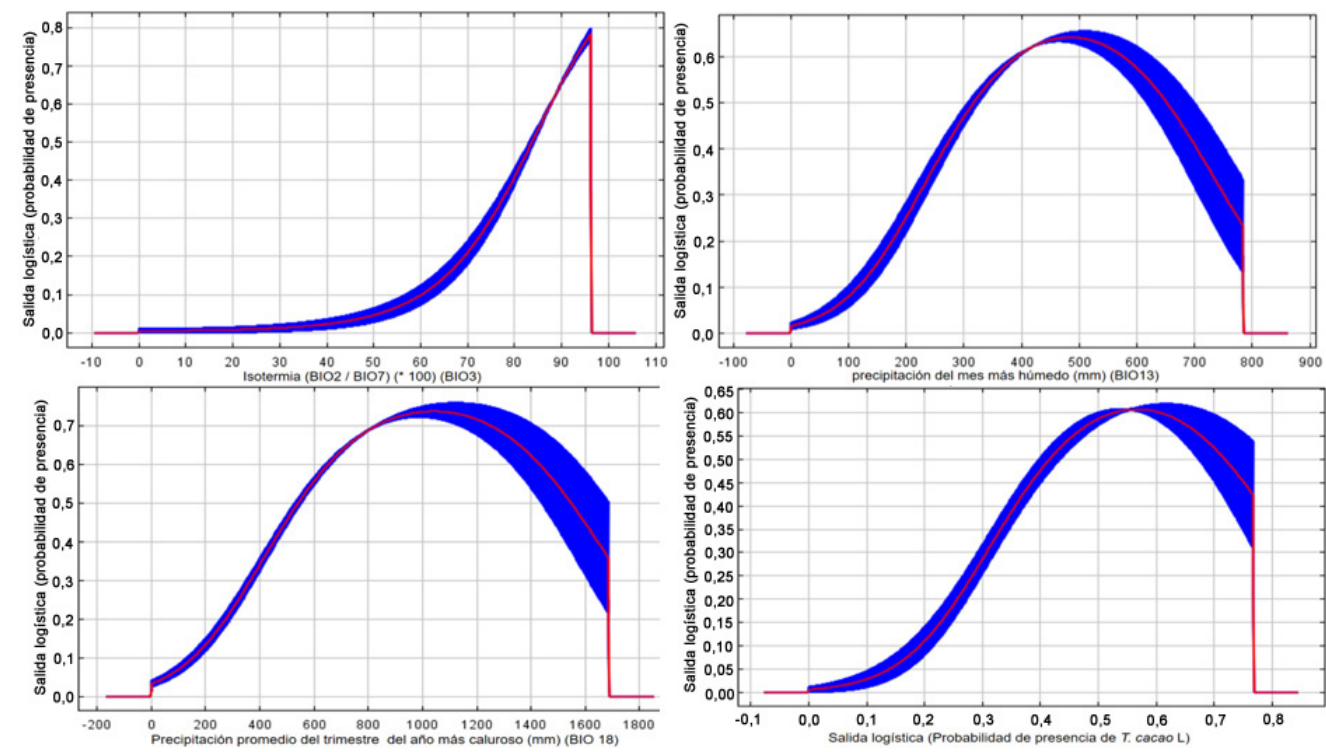

Figura 3. Curvas de respuesta de la probabilidad de ocurrencia relativa de la moniliasis (Moniliophthora roreri) en función de los predictores más importantes (valor Jackknife) en su modelo de distribución.

Figure 3. Response curves of the relative occurrence probability of moniliasis (Moniliophthora roreri) according to the most important predictors (Jackknife value) in its distribution model.

Las zonas con mayor idoneidad de hábitat para el desarrollo de la escoba de bruja en Brasil se ubican en los estados de Amazonas y Pará (probabilidad de 0,5 a 0,7), y más alta en las costas del estado de Bahía (0,8 a 1) (Figura 1). 


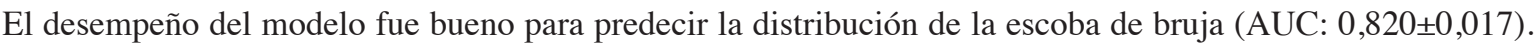
Las variables de mayor importancia en el modelo fueron el rango medio diurno (BIO2), la temperatura mínima del mes más frío (BIO6), y la precipitación del mes más seco (BIO14). Rangos diurnos estrechos de temperatura, con mínimas durante el mes más frío de $22{ }^{\circ} \mathrm{C}$ y precipitaciones de $100 \mathrm{~mm}$ durante el mes más seco, pueden influir positivamente en la probabilidad de ocurrencia de la escoba de bruja, sin ninguna relación directa entre una baja o alta probabilidad de presencia del cacao (Figura 4).
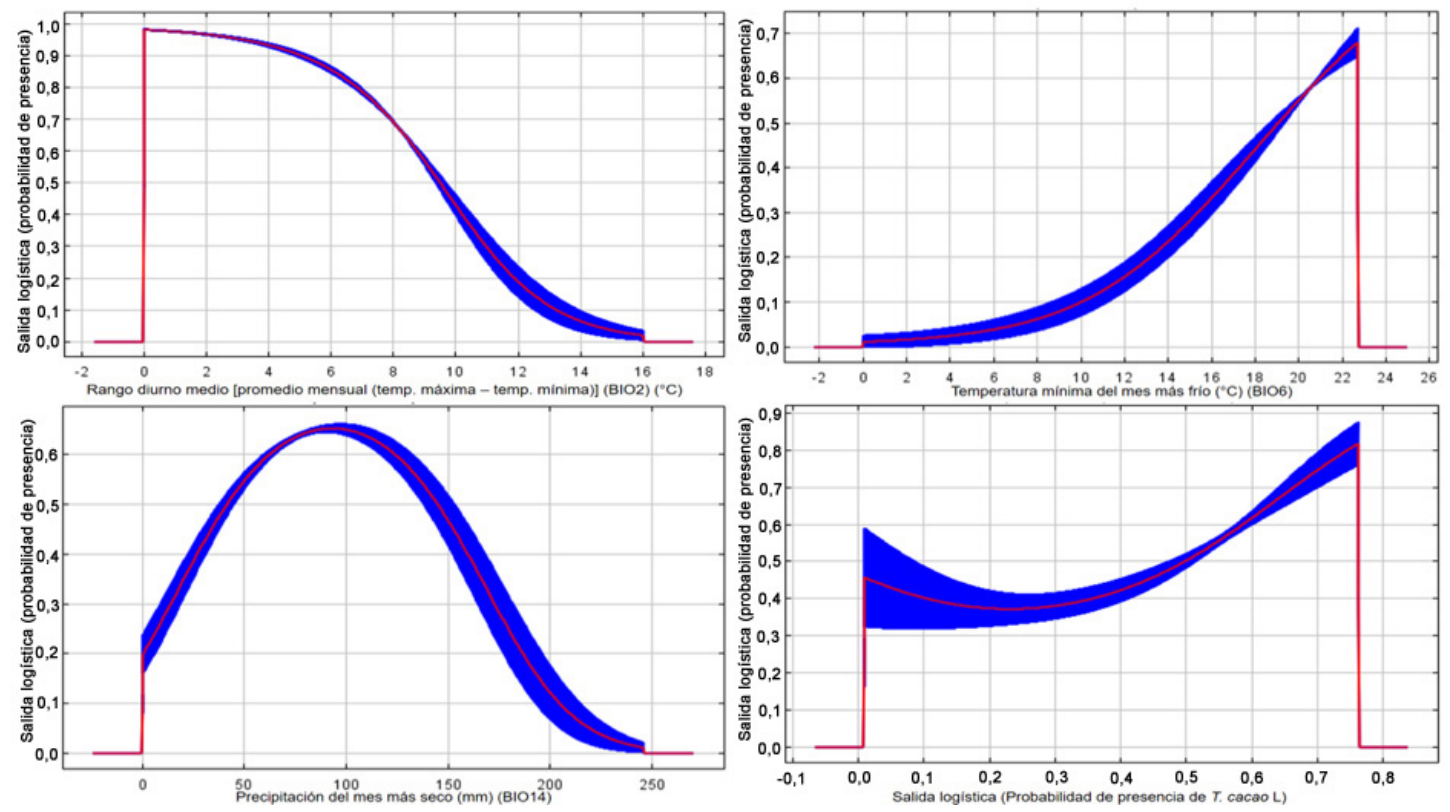

Figura 4. Curvas de respuesta de la probabilidad de ocurrencia relativa de la escoba de bruja (Moniliophthora perniciosa), en función de los predictores más importantes (valor Jackknife) en su modelo de distribución.

Figure 4. Response curves of the probability of relative occurrence of the witch's broom (Moniliophthora perniciosa) based on the most important predictors (Jackknife value) in its distribution model.

\section{Transferencia del modelo de $M$. roreri a Brasil}

Los estados de Brasil que registraron un mayor potencial de invasión de la moniliasis fueron Amazonas, Acre y zonas del estado Pará con probabilidades de ocurrencia del hongo del 0,56 a 0,9 (Figura 5).

\section{Transferencia del modelo de M. perniciosa a Centro y Suramérica}

Los países con mayores valores de idoneidad para el desarrollo de la escoba de bruja fueron Guyanas, Surinam, Panamá, Nicaragua, zonas costeras del Ecuador, estados de Táchira, Mérida y Zulia de Venezuela, los departamentos de Tolima, Neiva, Santander, Norte de Santander y zonas del Caribe de Colombia, con probabilidades de ocurrencia de 0,75 a 1 (Figura 5). 


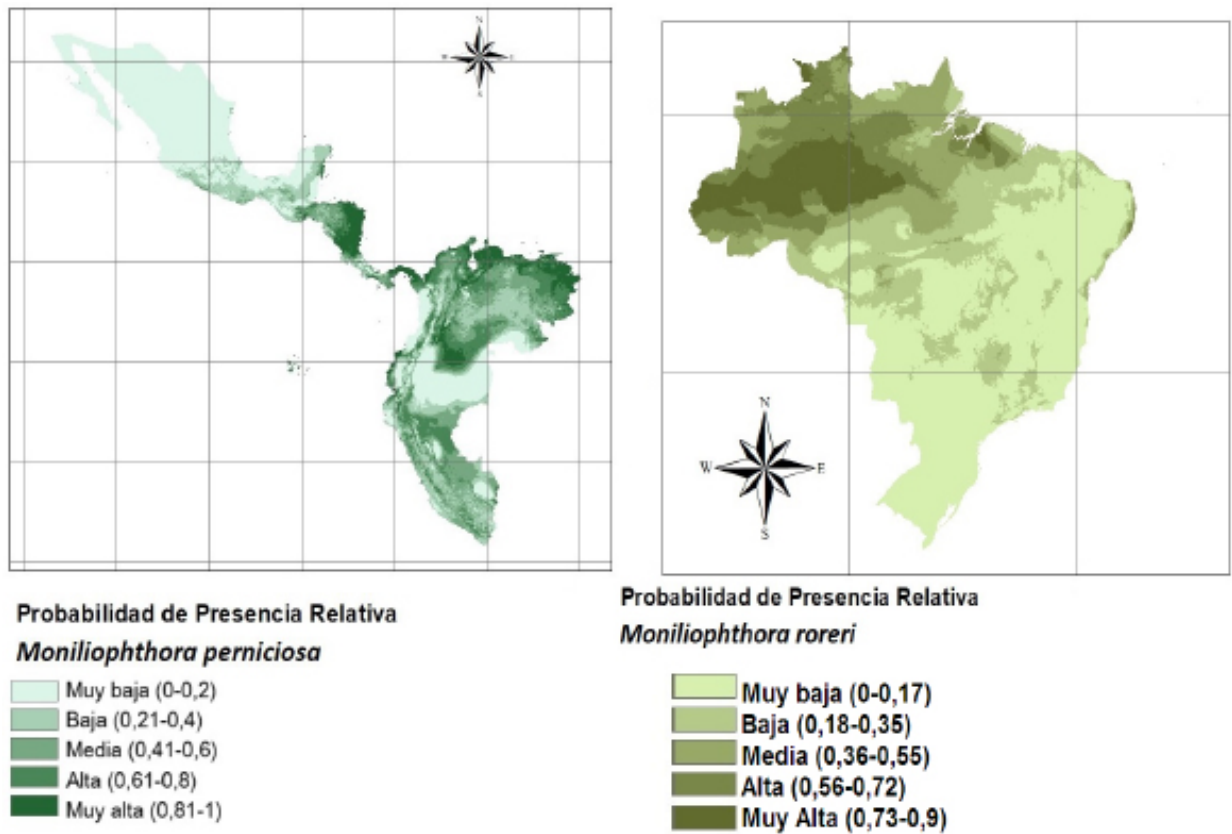

Figura 5. Transferencia del modelo de M. perniciosa en Brasil proyectado a áreas geográficas de Centro y Sudamérica, y del modelo de $M$. roreri a zonas de Brasil.

Figure 5. Transference of the model of M. perniciosa in Brazil projected to geographic areas of Central and South America, and of the model of $M$. roreri to Brazil areas.

\section{Transferencia del modelo de M. roreri y M. perniciosa a África}

Al realizar la transferencia de $M r$ hacia África se observó que la distribución potencial (probabilidad de ocurrencia de 0,3 a 0,7 ) del patógeno se ubicaría en los bosques lluviosos tropicales de la cuenca del río Congo, en países como Congo, República Democrática del Congo y Camerún, cercanos a la línea del Ecuador (Figura 6). Las zonas costeras de Costa de Marfil, Ghana y Nigeria serían lugares con un potencial medio (probabilidad (pr) de ocurrencia de 0,3 a 0,6 ) de invasión del patógeno. La enfermedad de la escoba de bruja podría distribuirse en países como Costa de Marfil, Congo, Gabón y Camerún (pr de presencia de 0,6 a 1) (Figura 6).

\section{Nichos fundamentales}

La visualización de los nichos permite observar el solapamiento de los espacios ambientales compartidos entre los patógenos y el cacao (Figura 7), sin embargo, la intersección de los volúmenes de los elipsoides difirió para cada especie del hongo, y de acuerdo a las variables ambientales usadas como nube de fondo. Cuando el nicho virtual se observó desde las variables ambientales que más influyeron en el modelo del cacao (Figura 7A), el nicho de $\mathrm{Mr}$ fue más similar al de la planta, en comparación al nicho de $M p$ (Cuadro 1).

El nicho fundamental de $M r$ fue más similar al del cacao (Cuadro 1) bajo condiciones abióticas de temperatura, en comparación al nicho de $M p$ (Figura 7C). Por otra parte, al analizar el nicho fundamental bajo variables climáticas de precipitación (Figura 7B), los nichos de $M p$ y $T c$ poseen un mayor valor de similitud, respecto al nicho de $M r$ (Cuadro 1). 


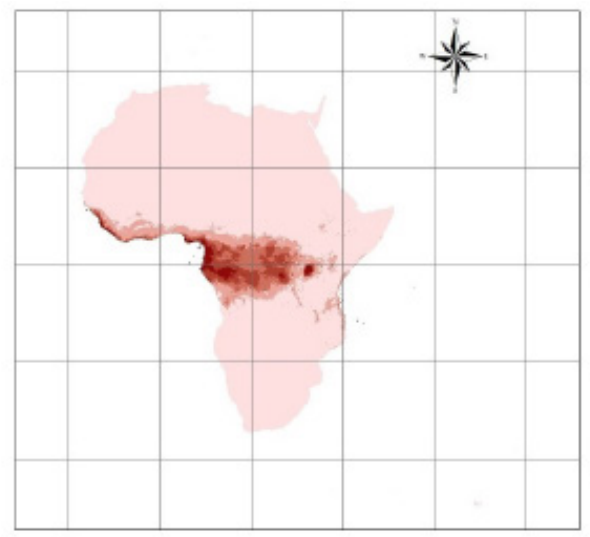

Probabilidad de Presencia Relativa

Moniliophthora roreri

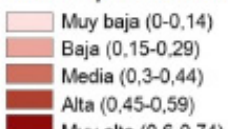

Muy alta $(0,6-0,74)$
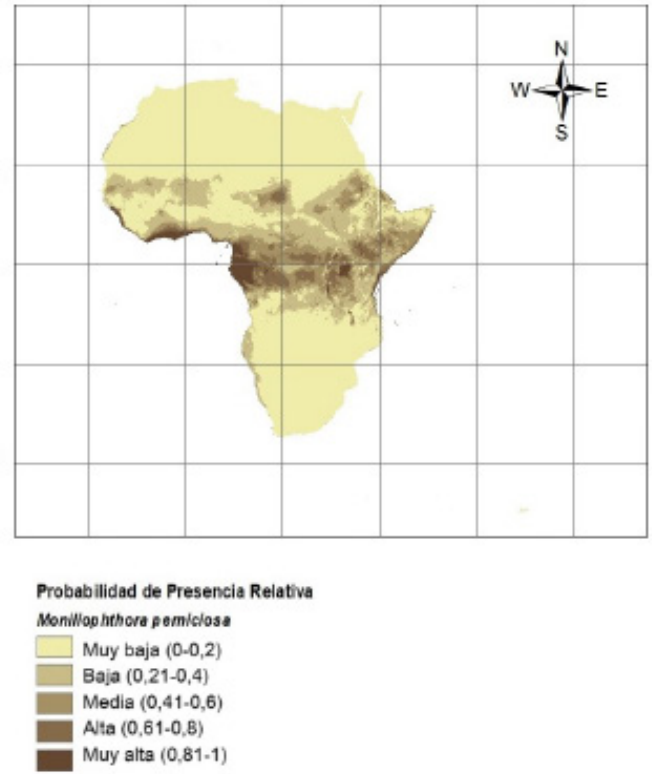

Figura 6. Transferencia del modelo de distribución potencial de M.roreri y M. perniciosa a África.

Figure 6. Transfer of the potential distribution model of M. roreri and M. perniciosa to Africa.

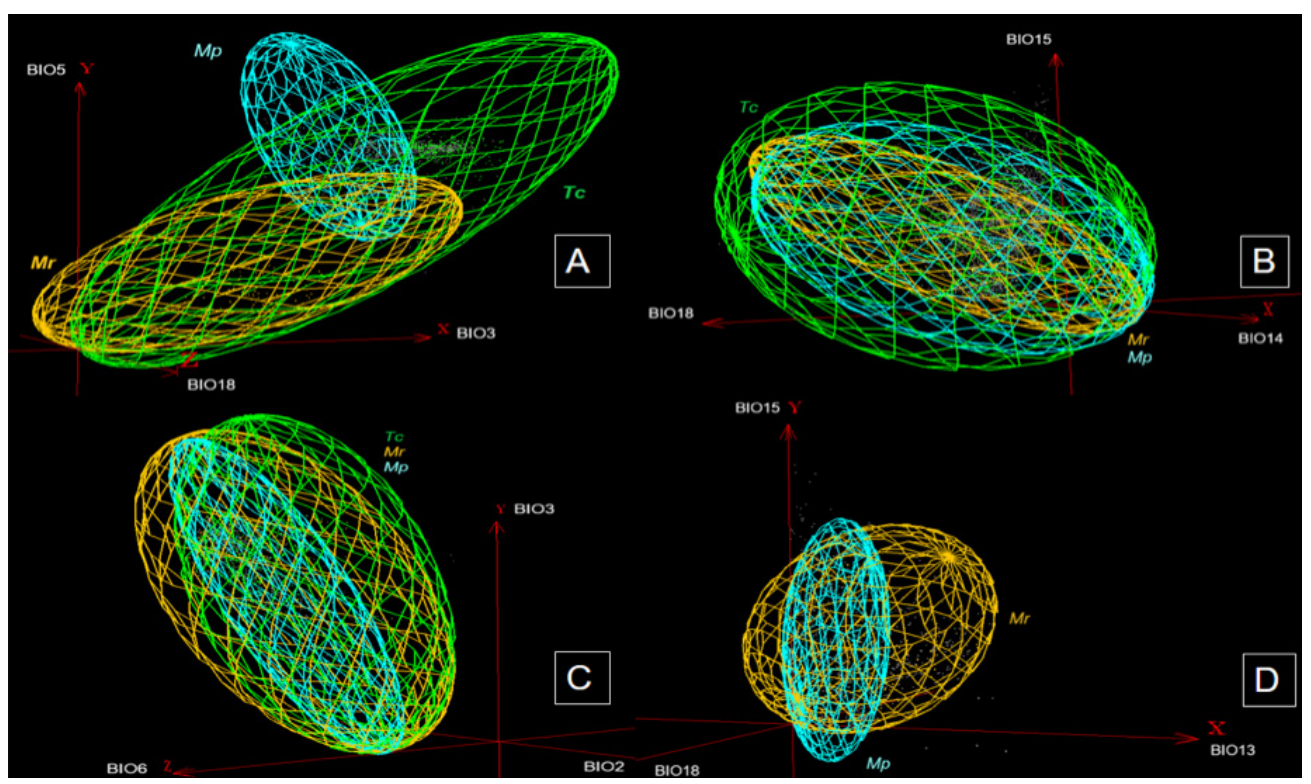

Figura 7. Nichos fundamentales virtuales basados en el elipsoide de mínimo volumen (EMV), construido a partir de registros de ocurrencias de $T$. cacao L. (Tc), M. roreri $(\mathrm{Mr})$ y M. perniciosa $(\mathrm{Mp})$, proyectados en el espacio ambiental (A) de las variables más importantes para el modelo del cacao, (B) de las condiciones abióticas de precipitación, (C) de la temperatura con mayor contribución de los tres modelos, y (D) con los factores más importantes para el modelo de M. roreri.

Figure 7. Virtual fundamental niches based on the minimum volume ellipsoid (MVE), constructed from occurrences records of T. cacao L. (Tc), M.roreri $(\mathrm{Mr})$ and M. perniciosa $(\mathrm{Mp})$, projected in the environmental space (A) of the most important variables for the cocoa model, (B) of abiotic precipitation conditions, (C) of the temperature with the greatest contribution of the three models, and (D) with the most important factors for the M.roreri model. 
Cuadro 1. Similitud de los nichos fundamentales de Moniliophthora roreri (Mr), Moniliophthora perniciosa (Mp) y Theobroma cacao L. $(T c)$, proyectados en distintos espacios ambientales.

Table 1. Similarity of the fundamental niches of Moniliophthora roreri (Mr), Moniliophthora perniciosa (Mp) and Theobroma cacao L. $(T c)$, projected in different environmental spaces.

\begin{tabular}{cccccc}
\hline Figura & Especies & ISJ & Figura & Especies & ISJ \\
\hline \multirow{3}{*}{$1 \mathrm{~A}$} & $M r-M p$ & 0,30 & & $M r-M p$ & 0,31 \\
& $M r-T c$ & 0,71 & $3 \mathrm{C}$ & $M r-T c$ & 0,50 \\
& $M p-T c$ & 0,42 & & $M p-T c$ & 0,30 \\
\hline \multirow{2}{*}{$2 \mathrm{~B}$} & $M r-M p-T c$ & 0,22 & $4 \mathrm{D}$ & $M r-M p-T c$ & 0,22 \\
& $M r-M p$ & 0,51 & $2 \mathrm{~A}$ & & 0,34 \\
& $M r-T c$ & 0,37 & $2 \mathrm{~B}$ & $M p-T c$ & 0,31 \\
& $M p-T c$ & 0,59 & & 0,61 \\
\hline
\end{tabular}

ISJ: Índice de Similitud de Jaccard (0-1) / ISJ: Jaccard Similarity Index (0-1).

Cuando se construyeron los nichos virtuales del cacao y los patógenos proyectados en las variables de cada área geográfica por separado, el elipsoide de $M p$ tuvo un mayor grado de intersección con el elipsoide del cacao (Figura 8B), mientras que el mismo ejercicio realizado para el nicho de $M r$ registró una baja similitud (Figura 8A).

Los elipsoides comparados entre los dos patógenos mostraron un nivel de solapamiento leve y niveles de similitud bajos al proyectarlos en el espacio ambiental del cacao (Figura 7A, Cuadro 1) y de $\mathrm{Mr}$ (Figura 7D, Cuadro 1), bajo las variables más importantes de temperatura (Figura 7C, Cuadro 1); mientras que los nichos de las dos especies de hongos fueron moderadamente similares (Figura 7B) en los espacios ambientales donde la precipitación fue el factor analizado.

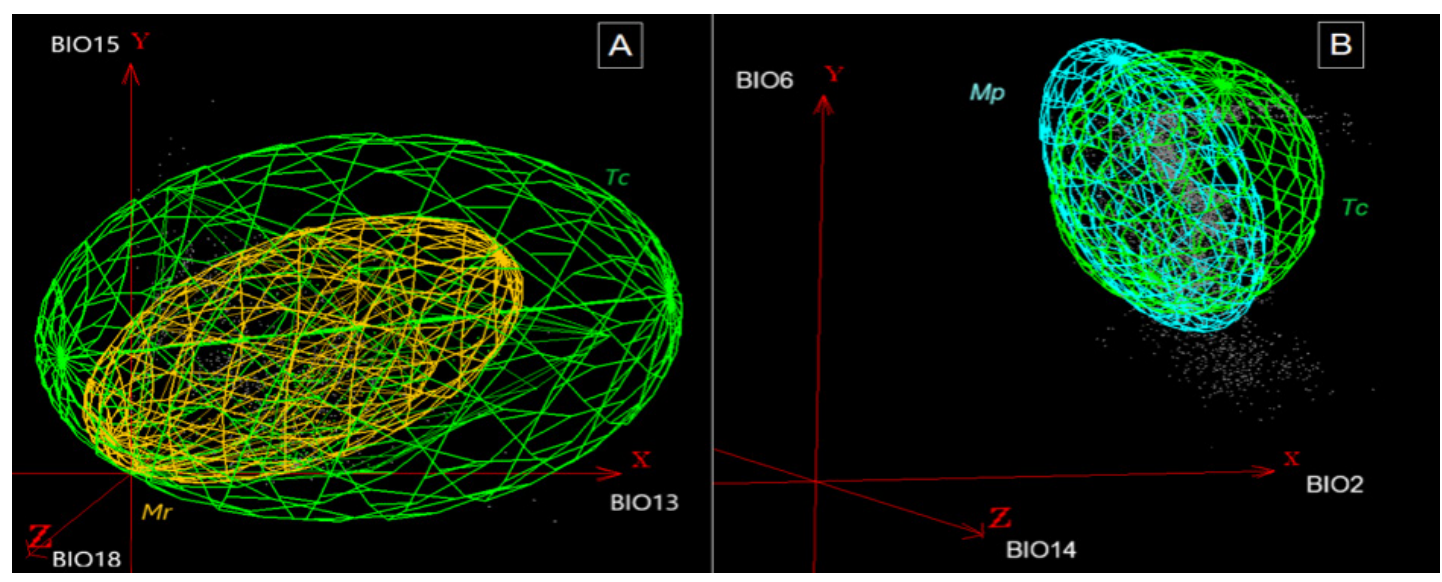

Figura 8. Nichos fundamentales virtuales basados en el elipsoide de mínimo volumen (EMV) a partir de registros de ocurrencias de T. cacao L $(T c)$, (A) M. roreri $(M r)$ y (B) M. perniciosa $(M p)$, proyectados en las variables más importantes del espacio ambiental de cada patógeno.

Figure 8. Virtual fundamental niches based on the minimum volume ellipsoid (MVE) from records of occurrences of $T$. cacao L (Tc), (A) M.roreri $(\mathrm{Mr})$ and (B) M. perniciosa $(\mathrm{Mp})$ projected on the most important variables of the environmental space of each pathogen. 
Existen espacios ambientales similares compartidos entre las tres especies (Figura 2A, 2B, 2C), al observar intersecciones entre los tres elipsoides, sin embargo, el nivel de similitud de los nichos fue bajo (Cuadro 1).

\section{Discusión}

Las regiones de mayor ocurrencia relativa del cacao están asociadas con los dos puntos de diversificación y de mayor diversidad genética de la especie, uno ubicado en el Amazonas alto de Perú y Colombia, y una segunda área ubicada en México y países de Centroamérica (Bartley, 2005; Motamayor et al., 2008; Thomas et al., 2012). Las curvas de respuesta arrojaron que la probabilidad de ocurrencia del cacao es mayor en zonas donde las lluvias son regulares durante las temporadas secas del año, donde la homogeneidad de la variación térmica en todos los meses del año es alta (isotermia) y las temperaturas máximas en el mes más seco son de 25 a $30{ }^{\circ} \mathrm{C}$, condiciones abióticas típicas de las regiones tropicales húmedas de los bosques del Amazonas, que constituyen el centro de origen del cacao (Motamayor et al., 2008; Zhang y Motilal, 2016) y que se encuentran en los rangos de estrés fisiológico de la planta (Schmidt et al., 1993).

Los hábitats idóneos para el establecimiento de M. roreri $(\mathrm{Mr})$ poseen una mayor estacionalidad de la precipitación. En las regiones donde las lluvias son constantes durante el año, la probabilidad de ocurrencia de $\mathrm{Mr}$ es alta, lo cual podría estar asociado a que en el ambiente se mantengan condiciones de humedad relativa adecuadas $\left(80\right.$ al 100,\%) durante tiempos de temperatura óptimos para la germinación de las esporas $\left(20\right.$ a $\left.28{ }^{\circ} \mathrm{C}\right)$ (Campuzano, 1980; Phillips-Mora, 1986). Estas condiciones ambientales influyen en el inicio de ciclos repetitivos de infección en los cultivos, como se ha observado en regiones con distribución bimodal de las lluvias (valles de Colombia), donde el patógeno ataca durante todo el año (Jaimes y Aranzazu, 2010) y con periodos policíclicos anuales de la enfermedad como los registrados en Costa Rica (Leandro, 2011).

En zonas con promedio de lluvias de 1000 a $1200 \mathrm{~mm}$ durante los tres meses del año más calientes, las probabilidades de ocurrencia de $M r$ son mayores, lo cual también estaría relacionado con los tiempos en los cuales se inicia un nuevo ciclo de infección secundaria. En la fase biótrofa del hongo, la espora requiere frecuencias de humedad relativas altas para germinar, principalmente durante los primeros estadios de crecimiento de los frutos jóvenes del cacao (chireles o pepinos) o mazorcas en desarrollo (entre los 0 y $10 \mathrm{~cm}$ de longitud) (Leandro-Muñoz et al., 2017).

Se ha descrito que las regiones cálidas y con alta humedad poseen una incidencia superior del patógeno (Cubillos, 2017). Las frecuencias de las precipitaciones y la humedad relativa del ambiente durante varias épocas del año, son factores importantes en el inicio de infecciones sucesivas (Jaimes y Aranzazu, 2010). La eliminación de la fuente de inóculo mediante la remoción de frutos en esporulación o momificados durante los períodos de transición entre una cosecha con árboles enfermos y un nuevo ciclo de fructificación, es una práctica importante en el control cultural de la moniliasis (Cubillos, 2017). Sin embargo, se ha reportado que las esporas de $\mathrm{Mr}$ poseen altos periodos de longevidad y dormancia (hasta tres meses en el suelo) (González, 1981), debido a sus características morfológicas (paredes celulares gruesas, con altos contenidos de melanina, masas polvosas) (Evans, 2007), las cuales les confieren un alto tiempo de persistencia en los hábitats (suelo y hojarasca) del agroecosistema, en espera de las condiciones adecuadas de humedad para su germinación y comenzar un nuevo ciclo de la enfermedad (Campuzano, 1980). Debido a lo anterior, es importante que en las zonas geográficas con climas de alta estacionalidad y con precipitaciones entre los 1000 y $1200 \mathrm{~mm}$ durante los meses más cálidos, se realicen, con alta frecuencia, buenas prácticas de control cultural tales como las podas de mantenimiento al dosel, fertilizaciones edáficas y la remoción de los frutos enfermos (Villamil et al., 2015).

Se han encontrado correlaciones positivas entre la humedad relativa y la incidencia de la moniliasis, con mayores porcentajes de incidencia durante los períodos donde la humedad relativa es del $90 \%$ antes de 49 días 
del registro del primer síntoma (Torres de-la-Cruz et al., 2011). Se han registrado correlaciones positivas entre las precipitaciones durante los dos o cuatro meses antes de un ciclo infectivo y la incidencia del patógeno (Evans et al., 1977; Porras y González, 1982). Lo anterior puede explicar que la variable de la precipitación del mes más húmedo sea importante en el modelo de nicho de $M r$.

La única variable de temperatura que tuvo una mayor contribución en la ganancia del modelo de $\mathrm{Mr}$ fue la isotermia. Un mayor porcentaje de isotermia (aprox. $100 \%$ ) puede influir positivamente en la probabilidad de presencia $(0,8)$ de $M r$. La isotermia es una medida de las condiciones de temperatura estables y homogéneas durante los meses del año de una región, y esta variable podría influir en la fase intermedia biotrófica del hongo e inicial de la necrotrófica, en las cuales el hongo necesita una temperatura relativamente constante durante el crecimiento micelial en el interior del fruto y su posterior proceso de esporulación externa (Leandro-Muñoz et al., 2017).

Las zonas de mayor probabilidad de ocurrencia de M.perniciosa $(\mathrm{Mp})$ del estado de Bahía, Brasil, son regiones donde se han caracterizado áreas agroecológicas aptas para el cultivo de cacao como Almada, Ipiau y Camacan (Andebrhan et al., 1999). Se ha demostrado mediante inoculaciones cruzadas de cepas de $M p$ en distintos materiales vegetales de cacao y en zonas geográficas alejadas, que la especie posee un alto grado de adaptación potencial en áreas de la región de Bahía al infectar e inducir altos grados de patogenicidad (Gramacho et al., 2016).

Una mayor probabilidad de ocurrencia de $M p$ está asociada a zonas con rangos estrechos de temperatura diurna (rangos entre 0 y $4{ }^{\circ} \mathrm{C}$ ) y a temperaturas mínimas del mes más frío cercanas o mayores a los $22^{\circ} \mathrm{C}$, factor ambiental que podría influir en que la temperatura se mantenga constante en el día, y se beneficien los largos periodos de incubación de la enfermedad, dado que la tasa de desarrollo y crecimiento del micelio de la fase biótrofa puede durar de uno a dos meses (Meinhardt et al., 2008). Por otra parte, la temperatura es un factor importante en la germinación de las basidiosporas, que ocurre entre los 22 y $24{ }^{\circ} \mathrm{C}$ (CABI, 2016).

La precipitación durante el mes más seco (BIO14) y la precipitación promedio del trimestre del año más frío (BIO19) fueron los factores más importantes en el modelo de $M p$. Las lluvias pueden ser importantes, ya que la formación de basidiocarpos puede ser inducida por condiciones de humedad e igualmente, la liberación de las basidiosporas es producida por los efectos mecánicos de las gotas de agua (CABI, 2016; Evans, 2016a). Se ha observado la proliferación de los cuerpos fructíferos en los árboles enfermos después de cuatro a seis semanas del tiempo de precipitaciones (Schmidt et al., 1993). Aunque un basidiocarpo no sobreviva mucho tiempo (tres días de sobrevivencia después de su maduración), una población de $M p$ en la planta puede desarrollar hasta treinta cuerpos fructíferos en cinco a siete días, y originarlos durante dos años o más tiempo durante las estaciones de precipitación (Evans, 2016a).

El comportamiento de las curvas de respuesta de la probabilidad de ocurrencia de los patógenos en función de la presencia relativa de las poblaciones de T. cacao L. fue distinto. La relación directa entre la ocurrencia relativa del cacao y M. roreri está asociada a la fuerte dependencia del hongo hacia los frutos del hospedero (Evans, 2016a). Se ha descrito que a mayor número de mazorcas disponibles en periodos de fructificación existe un incremento en la incidencia de la moniliasis (Leandro, 2011). Por el contrario, no se observó una relación entre la probabilidad de presencia del cacao y $M$. perniciosa. El hongo puede establecerse en zonas donde no se distribuye el cacao, ya que puede parasitar otras especies de plantas (Griffith et al., 2003), lo cual le confiere un mayor rango de distribución geográfica y de nicho fundamental en comparación con el modelo de nicho de M. roreri.

Las regiones donde el cacao ha sido introducido y que no corresponden a sus hábitats nativos, son las regiones donde los patógenos registraron una mayor probabilidad de presencia. Por ejemplo, la ocurrencia relativa de $\mathrm{Mr}$ fue mayor en las zonas del norte de Colombia (Antioquia y Santander), donde el cacao fue transportado e introducido por los indígenas desde el sur del Amazonas peruano durante el proceso de domesticación ocurrido en la época precolombina, al cruzar la barrera geográfica de los Andes (Clement et al., 2010); o en el caso de $M p$ por el desplazamiento del cultivo de cacao desde el amazonas noroccidental de Brasil hacia el oriente por las riberas del río Amazonas, llevado a cabo por monjes jesuitas (Bartley, 2005), o el desarrollo del cultivo tras la creación 
de la carretera transamazónica en los procesos de colonización humana en 1970 y 1980 en los estados de Pará y Rondonía (Bartley, 2005); zonas en las cuales se reportaron los valores más altos de ocurrencia relativa de $M p$.

Una probabilidad de presencia media $(0,5$ a 0,7$)$ de $M p$ se registró para las regiones del Amazonas colombiano y el Amazonas del Perú, zonas donde se encuentra la mayor riqueza de especies del género Theobroma (Thomas et al., 2012). Un mayor acceso a hospederos puede influir directamente en una mayor probabilidad de presencia del patógeno. El primer registro histórico oficial de escoba de bruja fue hecho en Surinam en el año 1895 (sugerido como posible centro de origen según Evans, 2016a; Artero et al., 2017). Posteriormente, la presencia del patógeno fue informada en las Guyanas (1905) y en Ecuador en 1921 (Anderbrhan et al., 1999), países en los cuales el modelo mostró una alta probabilidad de ocurrencia de $M p$.

Las zonas de potencial de $\mathrm{Mr}$ en Brasil coincidieron con los lugares de mayor producción de cacao del país y regiones amazónicas donde se encuentran climas húmedos tropicales. $M r$ no se distribuiría hacia regiones del sur y centro de Brasil, probablemente asociado a la presencia de estaciones secas definidas durante el año (Maddison et al., 1995).

El potencial de invasión de $M p$ tiene un patrón principalmente orientado a las zonas costeras de los países, con probabilidades de ocurrencia menores en zonas de mayores altitudes como los Andes de Sudamérica, en oposición a su especie hermana $M r$, ya que su rango de distribución está asociado a áreas de mayores altitudes y sus probabilidades de presencia son menores en las zonas costeras (Evans, 2016b).

Al realizar la transferencia de los modelos de nicho de los patógenos a las zonas geográficas de África, estos se podrían establecer en las cuencas del río Congo, al igual que las plantas de cacao, que son originarias de los bosques húmedos tropicales de la cuenca alta del río Amazonas (Zhang y Motilal, 2016). La probabilidad de ocurrencia relativa de $M p$ fue mayor comparada con las obtenidas de la transferencia de $M r$, y tendría un mayor potencial de invasión al distribuirse en más zonas geográficas del continente africano. El rango mayor de distribución posible de $M p$ se relaciona con su alta capacidad adaptativa en ambientes locales (Gramacho et al., 2016) de su nicho fundamental, a su capacidad de infectar varios tejidos de la planta y a la adaptación a climas con temporadas secas.

Los nichos fundamentales de los patógenos y el cacao poseen valores medios a relativamente altos de similitud, lo cual podría estar relacionado a la historia coevolutiva de la interacción parásito-hospedero (Evans, 2016a; b). El nicho ecológico de organismos parasitarios es afectado por los rangos y límites de las condiciones abióticas que tolera el hospedero (Wiens et al., 2010), como se observó en los solapamientos de los nichos al ser proyectados con variables como la isotermia y la precipitación en los tres meses más calurosos, que fueron importantes en los modelos de $T c$ y $M r$. Aunque existió similitud, existen espacios ambientales ocupados por los patógenos que no se solapan con los del cacao, y estos escenarios podrían estar relacionados con su condición como hemibiótrofos, ya que no son parásitos obligados y pasan por fases biotróficas, necrótrofas o saprofíticas, y probablemente en esta última fase del ciclo pueden crecer, persistir y formar poblaciones viables en otros hábitats como el suelo y la hojarasca, en los cuales no ha sido comprobado el crecimiento y reproducción de los patógenos. Asimismo, ambos hongos pueden ser capaces de alternar de hospedero y habitar espacios ambientales temporales distintos a los de las fases de fructificación del cacao, para el caso de $M r$, o espaciales, si existe un amplio acceso a otras especies de plantas, como en el Amazonas, en la situación de $M p$.

Los nichos virtuales de $M r$ y $M p$ tuvieron similitudes diferentes con el nicho del cacao al ser proyectados con distintas variables ambientales. Los nichos de $M r$ y $T c$ fueron más similares cuando se proyectó el elipsoide en los factores abióticos de temperatura, mientras que la similitud de los nichos de $M p$ y $T c$ fue mayor cuando se utilizaron variables de precipitación. Al contrastarlo con las variables de mayor importancia en la distribución (Jackknife en el algoritmo de MaxEnt), el comportamiento fue inverso, para $M r$ la precipitación influyó en su distribución y para $M p$ la temperatura. En el espacio ambiental, el nicho de $M r$ fue similar y estaría más adaptado a las condiciones de temperatura del cacao, pero su distribución dependió de las precipitaciones y por ende, es una variable importante 
en el modelo de nicho del hongo. Por el contrario, el nicho de $M p$ fue similar al del cacao en relación con la precipitación, pero su distribución está delimitada por las condiciones de temperatura de las zonas.

De la misma manera, existen diferencias en los nichos de ambos patógenos evaluadas por los bajos volúmenes de intersección de los elipsoides y el valor de similitud de Jaccard. Probablemente, entre las especies no existe conservadurismo filogenético del nicho analizándolo desde el modelo del cacao, ya que no se observó una tendencia de ambas especies, emparentadas filogenéticamente (Aime y Phillips-Mora, 2005), a retener rasgos ecológicos de sus nichos (Wiens et al., 2010) y, por el contrario, sí existieron diferencias en su adaptación a condiciones ecológicas particulares. Asimismo, se comprobó que especies con una alta relación taxonómica tienden a ser muy similares en sus rasgos funcionales, lo que incrementa la probabilidad de exclusión competitiva, teoría denominada la hipótesis filogenética de similitud limitante (Violle et al., 2011).

Es probable que la diferencia de los nichos fundamentales entre ambas especies de hongos fue consecuencia de un fenónemo de exclusión competitiva durante su evolución, sin embargo, esta hipótesis no fue evaluada en este estudio. Dos especies que coexisten y explotan un mismo recurso (árboles de cacao), se excluyen entre sí por competencia, y en un rango de tiempo, esta competencia podría seleccionar divergencias en los ejes dimensionales del espacio ambiental. A lo largo de la escala temporal evolutiva, el solapamiento de los nichos podría disminuir (Cornell, 2012), si las especies habitaran condiciones ambientales distintas, como variables de precipitación para $M r$ y de temperatura para $M p$. La exclusión competitiva podría estar influyendo en la baja incidencia de $M p$ en los cultivos de Sudamérica en regiones donde el patógeno ha sido introducido (Evans, 2016b), y donde la distribución de $M r$ es más amplia. Asimismo, la teoría podría explicar que $M r$ no haya sido reportada en plantas de cacao de Brasil, dado el caso de que fuera introducida accidentalmente en el país y coexistiera con $M p$. La fuerte competencia por el recurso de ambos hongos podría influir en intentos de invasiones fallidas por parte de ambas especies (Violle et al., 2011). Lo anterior debe ser investigado desde diferentes enfoques como experimentos de transplantes recíprocos, de la transferencia de los modelos de nicho a capas ambientales de años pasados, y desde el análisis de movimiento de material infectado y rutas de distribución entre regiones distintas a los centros de origen de los patógenos.

La distribución potencial de los patógenos y el cacao en algunos lugares coinciden, y el nicho fundamental de las tres especies puede solaparse y ser similares en una baja proporción. Por lo que, existen zonas geográficas y dimensiones en el ambiente que permiten el desarrollo de ambas enfermedades en un cultivo de cacao. Cuando el solapamiento de los nichos es alto (zonas de intersección de los elipsoides), podría existir limitación del recurso, la competencia excluiría al competidor más débil, probablemente en este caso a $M r$, ya que, si $M p$ infectara primero el árbol, afecta directamente la fisiología de la planta y por ende, la producción de frutos, reduciendo la disponibilidad del único recurso que puede explotar $M r$ del cacao (Evans, 2016a; b).

La baja similitud del nicho fundamental de los dos patógenos podrían ser consecuencia de un proceso de partición del nicho. La coexistencia de dos especies que comparten un mismo espacio geográfico, ambiental y un mismo hospedero, puede explicarse por el fenómeno de la partición del nicho fundamental y realizado (Adler et al., 2013). La partición del nicho ocurre cuando dos especies cercanas filogenéticamente ( $M r$ y $M p$ ) se especializan en la explotación de un recurso (infección diferencial en los órganos de las plantas de cacao) y en el establecimiento de sus poblaciones bajo condiciones ambientales específicas, es decir, en este estudio, de las variables bioclimáticas qué más influyeron en el modelo de nicho de los patógenos (la precipitación para la moniliasis y la temperatura para la escoba de bruja) (Adler et al., 2013). La partición del nicho fundamental de ambas especies estaría relacionada con los cambios de precipitación y temperatura que influyen directamente en la fenología del cacao. 


\section{Conclusiones}

Se identificaron las regiones geográficas con mayor distribución potencial de los patógenos y las características bioclimáticas que favorecerían su probabilidad de presencia en los cultivos de cacao de América. La distribución potencial de M. roreri está influenciada principalmente por las variables de precipitación, como la estacionalidad alta de las lluvias, la precipitación del mes más húmedo $(500-600 \mathrm{~mm})$, la precipitación del trimestre más cálido (1000-1200 mm). Para el modelo de $M$. perniciosa las variables asociadas a la temperatura fueron las más importantes. Variables como el rango diurno medio $\left(2-6^{\circ} \mathrm{C}\right)$ y la temperatura mínima del mes más frío $\left(22^{\circ} \mathrm{C}\right)$, influyeron en una mayor probabilidad de ocurrencia relativa de la escoba de bruja. Esta caracterización bioclimática e identificación geográfica es importante en la toma de decisiones para la ubicación de nuevos cultivos de cacao y en la implementación de adecuadas prácticas de manejo integrado del cultivo.

Existe una baja similitud entre los nichos fundamentales de $M$. roreri y $M$. perniciosa, reflejada en las diferencias de las variables blioclimáticas que mas aportan al modelo y en el bajo solapamiento de los elipsoides, que sugiere una partición del nicho fundamental y que podrían ser una causa en las diferencias del ciclo vital y de explotación del recurso de los patógenos.

Se determinó el potencial de invasión de los patógenos en las regiones costeras del río Congo en el continente africano, de M. roreri en las regiones de Acré y Pará en Brasil, además del riesgo de la amplia distribución de la escoba de bruja en Sudámerica. Descrita la posibilidad de colonizar nuevos espacios geográficos, es necesario que exista una regulación política y cultural sobre el transporte interregional de material vegetal y equipos de trabajo contaminados que pueden efectuar los pequeños y medianos agricultores cacaoteros, para evitar la introducción del patógeno en cultivos sanos y el desarrollo de infecciones secundarias en aquellos con un buen manejo fitosanitario.

Es necesario que se amplíen los estudios de Moniliophthora spp. en hábitats silvestres como los bosques amazónicos, y que se desarrollen registros de presencias con coordenadas geográficas y lugares específicos en los estudios, ya que existen tendencias a generalizar la ubicuidad de una enfermedad en una zona geográfica, lo cual imposibilita el uso de herramientas de modelamiento de distribuciones y de estudios biogeográficos en poblaciones de hongos fitopatógenos.

\section{Literatura citada}

Adler, P.B., A. Fajardo, A.R. Kleinhesselink, and N.J. Kraft. 2013. Trait-based tests of coexistence mechanisms. Ecol Lett. 16:1294-1306. doi:10.1111/ele.12157

Agrios, G.N. 2005. Plant pathology. $5^{\text {th }}$ ed. University of Florida, FL, USA.

Aime, M.C., and W. Phillips-Mora. 2005. The causal agents of witches' broom and frosty pod rot of cacao (chocolate, Theobroma cacao) form a new lineage of Marasmiaceae. Mycologia 97:1012-1022.

Ali, S.S., J. Shao, M.D. Strem, W. Phillips-Mora, D. Zhang, L.W. Meinhardt, and B.A. Bailey. 2015. Combination of RNAseq and SNP nanofluidic array reveals the center of genetic diversity of cacao pathogen Moniliophthora roreri in the upper Magdalena Valley of Colombia and its clonality. Front. Microbiol. 6:850. doi:10.3389/fmicb.2015.00850

Andebrhan, T., A. Figueira, M.M. Yamada, and D.B. Furtek. 1999. Molecular fingerprinting suggests two primary outbreaks of witches' broom disease (Crinipellis perniciosa) of Theobroma cacao in Bahia, Brazil. Eur. J. Plant Pathol. 105:167-175. doi:10.1023/A:1008716000479 
Artero, A.S., J.Q. Silva, P.S. Albuquerque, E.A. Bressan, G.A. Leal, A.M. Sebbenn, G.W. Griffith, and A. Figueira. 2017. Spatial genetic structure and dispersal of the cacao pathogen Moniliophthora perniciosa in the Brazilian Amazon. Plant Pathol. 66:912-923. doi:10.1111/ppa.12644

Barbosa, C.S., R.R. Fonseca, T.M. Batista, M.A. Barreto, C.S. Argolo, M.D. Carvalho, D.O. Amaral, E.M. Silva, E. Arévalo-Gardini, K.S. Hidalgo, G.R. Franco, C.P. Pirovani, F. Micheli, and K.P. Gramacho. 2018. Genome sequence and effectorome of Moniliophthora perniciosa and Moniliophthora roreri subpopulations. BMC Genomics 19:509. doi:10.1186/s12864-018-4875-7

Bartley, G.D. 2005. The genetic diversity of cacao and its utilization. CABI Publishing, Wallingford, GBR.

Bogosian, V., E.C. Hellgren, M.W. Sears, and R.W. Moody. 2012. High-resolution niche models via a correlative approach: Comparing and combining correlative and process-based information. Ecol. Model. 237-238:63-73. doi:10.1016/j. ecolmodel.2012.04.017

Brown, J.L. 2014. SDMtoolbox: a python-based GIS toolkit for landscape genetic, biogeographic, and species distribution model analyses. Methods Ecol Evol. 5:694-700. doi:10.1111/2041-210X.12200

CABI. 2016. Global module. 7nd ed. CABI, Oxfordshire, GRB.

Campuzano, H. 1980. La moniliasis del cacao. Cacaotero Colomb. 13:21-24.

Clement, C.R., M. de-Cristo-Araújo, G.C. d'Eeckenbrugge, A. Alves-Pereira, and D. Picanco-Rodrigues. 2010. Origin and domestication of native Amazonian crops. Diversity 2:72-106. doi:10.3390/d2010072

Cornell, H. 2012. Niche overlap. In: A. Hastings, and L. Gross, editors, Encyclopedia of theoretical ecology (No. 4). University of California Press, CA, USA. p. 489-497.

Cubillos, G. 2017. Frosty pod rot, disease that affects the cocoa (Theobroma cacao) crops in Colombia. Crop. Prot. $96: 77-82$. doi:10.1016/j.cropro.2017.01.011

Enríquez, G.A., and C.A. Suárez. 1978. Monilia disease of cocoa in Costa Rica. Turrialba 28:339-340.

Escobar, L.E., and M.E. Craft. 2016. Advances and limitations of disease biogeography using ecological niche modeling. Front. Microbiol. 7:1174. doi:10.3389/fmicb.2016.01174

Evans, H.C. 1986. A reassessment of Moniliophthora (Monilia) pod rot of cocoa. Cocoa Growers’ Bull. 37:4-43.

Evans, H.C. 2007. Cacao diseases - the trilogy revisited. Phytopathology 97:1640-1643. doi:10.1094/PHYTO-97-12-1640

Evans, H.C. 2016a. Witches' Broom disease (Moniliophthora perniciosa): History and biology. In: B. Bayley et al., editors, Cacao diseases: A history of old enemies and new encounters. Springer International Publishing, Basel, CHE. p. $137-177$. doi:10.1007/978-3-319-24789-2_5

Evans, H.C. 2016b. Frosty pod rot (Moniliophthora roreri). In: B. Bayley et al., editors, Diseases: A history of old enemies and new encounters. Springer International Publishing, Basel, CHE. p. 63-96. doi:10.1007/978-3-319-24789-2_5

Evans, H.C., J.L. Bezerra, and R.W. Barreto. 2013. Of mushrooms and chocolate trees: aetiology and phylogeny of witches' broom and frosty pod diseases of cacao. Plant Pathol. 62:728-740. doi:10.1111/ppa.12010

Evans, H.C., D.F. Edwards and M. Rodríguez. 1977. Research on cocoa diseases in Ecuador: Past and present. PANS 23:68-80. doi: 10.1080/09670877709412399

Evans, H.C., K.A. Holmes, W. Phillips-Mora, and M.J. Wilkinson, M.J. 2002. What's in a name, Crinipellis, the final resting place for the frosty pod rot pathogen of cocoa? Mycologist 16:148-152. doi:10.1017/S0269-915X(02)00409-3

Fick, S.E., and R.J. Hijmans. 2017. Worldclim 2: New 1-km spatial resolution climate surfaces for global land areas. Int. J. Climatol. 2017:5086. doi:10.1002/joc.5086 ISSN 2215-3608 doi:10.15517/am.v30i3.35038 
GBIF. 2018. Occurrence download. GBIF, DNK. doi:10.15468/dl.jka55n

González, L.C. 1981. Efecto de las fuentes de inóculo sobre las posibilidades de combate de la moniliasis del cacao. Acta de la Primera Jornada de Investigación. Universidad de Costa Rica, San José, CRI.

Gramacho, K.P., L.E.M. Newman, F.S. da-Silva, U.V. Lopes, J.L. Pires, and L. Pereira. 2016. Pathogenic variability of Moniliophthora perniciosa in three agroecological zones of the cacao region of Bahia, Brazil. Crop Breed. Appl. Biotechnol. 16:7-13. doi:10.1590/1984-70332016v16n1a2

Griffith, G.W., J. Nicholson, A. Nenninger, R.N. Birch, and J.N Hedger. 2003. Witches' brooms and frosty pods: two major pathogens of cacao. New Zeal. J. Bot. 41:423-35. doi:10.1080/0028825X.2003.9512860

Hutchinson, G.E. 1957. Concluding remarks. Cold Spr. Harb. Symp. Quant. Biol. 22:415-442. doi:10.1101/SQB.1957.022.01.039

Jaimes, Y., and F. Aranzazu. 2010. Manejo de las enfermedades del cacao (Theobroma cacao L.) en Colombia, con énfasis en monilia (Moniliophthora roreri). Corpoica, COL.

Kumar, S., L.G. Neven, and W.L. Yee. 2014. Evaluating correlative and mechanistic niche models for assessing the risk of pest establishment. Ecosphere 5(7):1-23. doi:10.1890/ES14-00050.1

Leal, G.A., P.S. Albuquerque, and A. Figueira. 2007. Genes differentially expressed in Theobroma cacao associated with resistance to witches' broom disease caused by Crinipellis perniciosa. Mol. Plant Pathol. 8:279-292. doi:10.1111/j.13643703.2007.00393.x

Leandro, M.E. 2011. Efecto de los factores macro y microclimáticas y las características productivas del cacao sobre la epidemiología de la moniliasis. Tesis M.Sc., CATIE, Turrialba, CRI.

Leandro-Muñoz, M.E., P. Tixier, A. Germon, V. Rakotobe, W. Phillips-Mora, S. Maximova, and A. Jacques. 2017. Effects of microclimatic variables on the symptoms and signs onset of Moniliophthora roreri, causal agent of Moniliophthora pod rot in cacao. PLoS One. 12(10):e0184638. doi:10.1371/journal.pone.0184638

Maddison, A.C., G. Macías, C. Moreira, R. Arias, and R. Neira. 1995. Cocoa production in Ecuador in relation to dryseason escape from pod rot caused by Crinipellis perniciosa and Moniliophthora roreri. Plant Pathol. 44:982-98. doi:10.1111/j.1365-3059.1995.tb02657.x

Meinhardt, L.W., J. Rincones, B.A. Bailey, M.C. Aime, G.W. Griffith, D. Zhang, and G.A.G. Pereira. 2008. Moniliophthora perniciosa, the causal agent of witches' broom disease of cacao: what's new from this old foe? Mol. Plant Pathol. 9:577588. doi:10.1111/j.1364-3703.2008.00496.x

Motamayor, J.C., P. Lachenaud, J.W. da-Silva-e-Mota, R. Loor, D.N. Kuhn, J.S. Brown, and R.J. Schnell. 2008. Geographic and genetic population differentiation of the Amazonian chocolate tree (Theobroma cacao L). PLoS One. 3(10):e3311. doi:10.1371/journal.pone.0003311

Orellana, R. 1956. Occurrence of Monilia pod rot and other cacao diseases in eastern Panama. FAO Plant Protect. Bull. 4:168169.

Osorio-Almanza, L., O. Burbano-Figueroa, A.M. Arcila, M.A. Vásquez, F. Carrascal-Pérez, y J. Romero. 2017. Distribución espacial del riesgo potencial de marchitamiento del aguacate causado por Phytophthora cinnamomi en la subregión de Montes de María, Colombia. Rev. Colomb. Cienc. Hortic.11:273-285. doi:10.17584/rcch.2017v11i2.7329.

Osorio-Solano, C., C.A. Orozco-Castaño, G.A. López-Gartner, y F.A. Rivera-Páez. 2012. Variabilidad genética de Moniliophthora perniciosa (Stahel) Aime y Phillips-Mora, comb. nov. (Agaricales - Marasmiaceae) en variedades de cacao (Theobroma cacao L.). Acta Agron. 61:93-101. 
Patrocínio, N.B., P.C. Ceresini, L.S. Gomes, M.V. Resende, E.G. Mizubuti, and K.P. Gramacho. 2017. Population structure and migration of the witches' broom pathogen Moniliophthora perniciosa from cacao and cultivated and wild solanaceous hosts in southeastern Brazil. Plant Pathol. 66:900-911. doi:10.1111/ppa.12636

Phillips, S.J., P.R. Anderson, and R.E. Schapire. 2006. Maximum entropy modeling of species geographic distributions. Ecol Model. 190:231-259. doi:10.1016/j.ecolmodel.2005.03.026

Phillips, S.J., and M. Dudík. 2008. Modeling of species distributions with Maxent: new extensions and a comprehensive evaluation. Ecography 31:161-175. doi:10.1111/j.0906-7590.2008.5203.x

Phillips-Mora, W. 1986. Evaluación de la resistencia de cultivares de cacao (Theobroma cacao L.) a Moniliophthora roreri (Cif. y Par.). Tesis M.Sc., Universidad de Costa Rica, San José, CRI.

Phillips-Mora, W., M.C. Aime, and M.J. Wilkinson. 2007. Biodiversity and biogeography of the cacao (Theobroma cacao) pathogen Moniliophthora roreri in tropical America. Plant Pathol. 56:911-922. doi:10.1111/j.1365-3059.2007.01646.x

Phillips-Mora, W., F. Baqueros, R.L. Melnick, and B.A. Bailey. 2015. First report of frosty pod rot caused by Moniliophthora roreri on cacao in Bolivia. New Dis. Rep. 31:29. doi:10.5197/j.2044-0588.2015.031.029

Phillips-Mora, W., J. Cawich, W. Garnett, and M.C. Aime. 2006a. First report of frosty pod rot (moniliasis disease) caused by Moniliophthora roreri on cacao in Belize. Plant Pathol. 55:584-584. doi:10.1111/j.1365-3059.2006.01378.x

Phillips-Mora, W., A. Coutiño, C.F. Ortiz, A.P. López, J. Hernández, and M.C. Aime. 2006b. First report of Moniliophthora roreri causing frosty pod rot (moniliasis disease) of cocoa in Mexico. Plant Pathol. 55:584-584. doi:10.1111/j.13653059.2006.01418.x

Porras, V.H., y L. González. 1982. Capacidad de liberación de mazorcas enfermas dejadas en el árbol de cacao. Actas de la V Reunión Anual de Agronomía. Colegio de Ingenieros Agrónomos, San José, CRI.

Purdy, L.H., and R.A. Schmidt. 1996. Status of cacao witches broom: biology, epidemiology, and management. Annu. Rev. Phytopathol. 34:573-94. doi:10.1146/annurev.phyto.34.1.573

Qiao, H., A. Peterson, C. Townsend, P. Lindsay, J. Soberón, L. Ji, and L.E. Escobar. 2016. NicheA: creating virtual species and ecological niches in multivariate environmental scenarios. Ecography 39:805-813. doi:10.1111/ecog.01961

Scarpari, L. M., L.W. Meinhardt, P. Mazzafera, A.W.V. Pomella, M.A. Schiavinato, J.C.M Cascardo, and G.A.G. Pereira. 2005. Biochemical changes during the development of witches' broom: the most important disease of cocoa in Brazil caused by Crinipellis perniciosa. J. Exp. Bot. 56:865-877. doi:10.1093/jxb/eri079

Schmidt, R.A., S.A. Rudgard, A.C. Maddison, and T. Andebrhan. 1993. Comparative epidemiology of the witches' broom pathosystem. In: S.A. Rudgard et al., editors, Disease management in cocoa. Springer, Dordrecht, NLD. p. 131-156. doi:10.1007/978-94-011-2126-2

Shaw, M.W., and A.E. Vandenbon. 2007. A qualitative host-pathogen interaction in the Theobroma cacao-Moniliophthora perniciosa pathosystem. Plant Pathol. 56:277-285. doi:10.1111/j.1365-3059.2006.01549.x

Silva, P. 1987. Cacau e lagarto e vassoura-de-bruxa: registros feitos por Alexandre Rodrigues Ferreira em 1785 e 1787 na Amazonia. Bol. Tecnol. CEPEC 146:3-21.

Soberón, J. 2007. Grinnellian and Eltonian niches and geographic distributions of species. Ecol. Lett. 10:1115-1123. doi:10.1111/j.1461-0248.2007.01107.x

Soberón, J., and A.T. Peterson. 2005. Interpretation of models of fundamental ecological niches and species' distributional areas. Biodiver. Inform. 2:1-10. doi:10.17161/bi.v2i0.4 
Suárez-Contreras, L.Y. 2016. Identificación molecular de aislamientos de Moniliophthora roreri en huertos de cacao de Norte de Santander, Colombia. Acta Agron. 65(1):51-57. doi:10.15446/acag.v65n1.47994

Thomas, E., M. van-Zonneveld, J. Loo, T. Hodgkin, G. Galluzzi G, and J. van-Etten. 2012. Present spatial diversity patterns of Theobroma cacao L. in the Neotropics reflect genetic differentiation in pleistocene refugia followed by human-influenced dispersal. PLoS One. 7(10):e47676. doi:10.1371/journal.pone.0047676

Torres-de-la-Cruz, M., C.F. Ortiz-García, D. Téliz-Ortiz, A. Mora- Aguilera, and C. Nava-Díaz. 2011. Temporal progress and integrated management of frosty pod rot (Moniliophthora roreri) of cocoa in Tabasco, Mexico. J. Plant Pathol. 93:31-36. doi:10.4454/jpp.v93i1.270

Villamil, J., L. Sierra, Y. Olarte, A. Mosquera, J. Fajardo, E. Pinzon, E. Mosquera, y J. Martínez. 2015. Integración de prácticas culturales y control biológico para el manejo de Moniliophthora roreri CIF \& PAR. Rev. Cienc. Agr. 32(2):13-25. doi:10.22267/rcia.153202.9

Violle, C., D.R. Nemergut, Z. Pu, and L. Jiang. 2011. Phylogenetic limiting similarity and competitive exclusion. Ecol. Lett. 14:782-787. doi:10.1111/j.1461 0248.2011.01644.x

Wiens, J.J., D.D. Ackerly, A.P. Allen, B.L. Anacker, L.B. Buckley, H.V. Cornell, E.I. Damschen, T. Jonathan-Davies, J. Grytnes, S.P. Harrison, B.A. Hawkins, R.D. Holt, C.M. McCain, and P.R. Stephens. 2010. Niche conservatism as an emerging principle in ecology and conservation biology. Ecol. Lett. 13:1310-1324. doi:10.1111/j.1461-0248.2010.01515.x

Zhang, D., and L. Motilal. 2016. Origin, dispersal, and current global distribution of cacao genetic diversity. In: B. Bayley et al., editors, Diseases: A history of old enemies and new encounters. Springer International Publishing, Basel, CHE. p. 3-31. doi:10.1007/978-3-319-24789-2_1 